\title{
Optimally designed interface of lithium rich layered oxides for lithium ion battery
}

\author{
Zhenjiang He ${ }^{*}$, Jing Ping, Zhaojun Yi, Cheng Peng, Chensi Shen, Jianshe Liu ${ }^{\dagger}$
}

\begin{abstract}
Particle morphology structure design combined with surface modification has been applied to improve the electrochemical properties of lithium rich layered oxides. Hollow spherical lithium rich layered $\mathrm{Li}_{1.2} \mathrm{Mn}_{0.54} \mathrm{Ni}_{0.13} \mathrm{Co}_{0.13} \mathrm{O}_{2}$ oxides with different shell thickness are synthesized by co-precipitation followed by calcination. The morphology and interior structure have been investigated by SEM and cross section, and their electrochemical properties have been evaluated to identify an appropriate shell thickness. Furthermore, a $\mathrm{Zr}$ compound coating layer has been applied to modify the interface between corrosive electrolyte and hollow spherical particles with an appropriate shell thickness. The Electrochemical impedance spectroscopy shows hollow spherical structure and $\mathrm{Zr}$ compound coating layer both can modificate the electronic and ionic transmission capacities and inhibit their deterioration during charge-discharge process at the same time. The HRTEM tests indicate that hollow spherical structure and $\mathrm{Zr}$ compound coating layer can dramaticlly suppress Mn dissolution in electrolyte and make the crystal structure more stable during the electrode process. Therefore, a surface modification combine with the hollow spherical structure (with an appropriate shell thickness) can effectively enhance these electrochemical properties of lithium ion layered oxides.
\end{abstract}

1 
Keywords: Lithium ion battery; Lithium rich layered oxide; Hollow spheres; Surface modification

\section{Introduction}

With the extensive application of lithium ion battery, more and more attentions are being paid on its performance especially the capacity. Present commercial cathode materials, such as $\mathrm{LiCoO}_{2}$ $/ \mathrm{LiMn}_{2} \mathrm{O}_{4} / \mathrm{LiNi}_{0.5} \mathrm{Co}_{0.2} \mathrm{Mn}_{0.3} \mathrm{O}_{2} / \mathrm{LiFePO}_{4}$, displays a specific capacity under $200 \mathrm{mAh} \mathrm{g}{ }^{-1}$, which is far below that of anode carbon materials.[1-3] Therefore, it is urgent to develop new cathode materials with larger capacity. In recent years, many researches concentrated on the lithium rich manganese layered oxides which delivered a discharge capacity range from 250 to $300 \mathrm{mAh}$ $\mathrm{g}^{-1}$.[4-9] However, the existence of electrochemical inactive $\mathrm{Li}_{2} \mathrm{MnO}_{3}$ results in the poor electron conductivity and low lithium ion diffusion coefficient, and then makes lithium rich manganese layered oxides show unsatisfactory rate capacity.[10, 11]

In the current study, elements doping, surface modification, and material nanocrystallization have been applied to improve the electrochemical properties of lithium rich manganese layered oxides.[12-16] Elements doping primarily used to enhance the crystal structure stability of materials during the electrode process, which can stabilize discharge plateau and achieving the stable energy density of the cathode, but has limited contribution to rate capacity. Carbon[17, 18] and graphene[19, 20] coating can facilitate both electronic and ionic conductivity leading to improve rate performance, but the effect on the corrosion resistance do not evaluated. Nanoparticles greatly shorten the lithium ion diffusion path and make particles contact with electrolyte well, but nanoparticle means large specific surface area, which could certainly destabilize materials in electrolyte, especially when the cut-off voltage is higher than $4.5 \mathrm{~V}$. 
Furthermore, it is more difficult to coat a protective layer on the surface of material since the particle size goes smaller and irregular, and then results in more exposed particle surfaces in corrosive electrolyte. [21]

Firstly, we propose an optimal designed hollow spherical structure for the lithium rich manganese layered oxide. The shell thickness of hollow spherical particles is range from 1.2 to 2.5 $\mu \mathrm{m}$, which are tuned by controlling the architecture of precursor. Although the resistance for lithium ion diffusion grow with the thickness of shell, structure collapses of hollow spherical particles should be found easier to occur during powder processing when shell thickness declined to a certain value, which may lead to more surface area be exposed to electrolyte. Therefore, an appropriate shell thickness is necessary for hollow spherical materials to resist the corrosion from electrolyte, and own good electronic and ionic conductivity at the same time. Secondly, a high $\mathrm{Li}^{+}$ diffusion coefficient $\mathrm{Zr}$ compound has been coated on the surface of hollow spherical $\mathrm{Li}_{1.2} \mathrm{Mn}_{0.54} \mathrm{Ni}_{0.13} \mathrm{Co}_{0.13} \mathrm{O}_{2}$ particles, which can further enhance the protection of hollow spherical $\mathrm{Li}_{1.2} \mathrm{Mn}_{0.54} \mathrm{Ni}_{0.13} \mathrm{Co}_{0.13} \mathrm{O}_{2}$ particles away from corrosive electrolyte. Obviously, this optimal design of particle surface can guarantee lithium rich manganese layered oxides a better electrochemical performance, which is significant in its development.

\section{Experiment}

The $\mathrm{Li}_{1.2} \mathrm{Mn}_{0.54} \mathrm{Ni}_{0.13} \mathrm{Co}_{0.13} \mathrm{O}_{2}$ sample is prepared by a solid state reaction from lithium carbonate and manganese-nickel-cobalt carbonate $\mathrm{Mn}_{0.54} \mathrm{Ni}_{0.13} \mathrm{Co}_{0.13}\left(\mathrm{CO}_{3}\right)_{0.8}$. The precursor of $\mathrm{Mn}_{0.54} \mathrm{Ni}_{0.13} \mathrm{Co}_{0.13}\left(\mathrm{CO}_{3}\right)_{0.8}$ was synthesized by co-precipitation method. The desired amount of $\mathrm{MnSO}_{4} \cdot \mathrm{H}_{2} \mathrm{O}, \mathrm{NiSO}_{4} \cdot 6 \mathrm{H}_{2} \mathrm{O}$ and $\mathrm{CoSO}_{4} \cdot 7 \mathrm{H}_{2} \mathrm{O}$ were dissolved in de-ionized water. The aqueous solution of sodium carbonate was used as the precipitator and an aqueous solution of ammonium 
bicarbonate served as the chelating agent (kept around $0.8 \mathrm{~mol} \mathrm{~L}^{-1}$ during the whole precipitation process). The solutions were mixed slowly in a continuously stirred $50 \mathrm{~L}$ tank reactor under air atmosphere, and the temperature and $\mathrm{pH}$ value of the mixed solution were kept at $55^{\circ} \mathrm{C}$ and 8.0 at front $3 \mathrm{~h}$ to form the loose core, and then turn $\mathrm{pH}$ to 8.5 at next stage $(1,3$ and $7 \mathrm{~h})$ to form the compact shell, and the obtained carbonate precursors are named as H1-1, H2-1 and H3-1 (conventional particles: kept at $55^{\circ} \mathrm{C}$ and 8.5 during the program, named as $\mathrm{H} 0-1$ ). The precursors and lithium carbonate were mixed in the molar ratio of $\mathrm{Li} /(\mathrm{Mn}+\mathrm{Ni}+\mathrm{Co})=1.56$, and annealed at $500{ }^{\circ} \mathrm{C}$ for $6 \mathrm{~h}$ firstly and $950{ }^{\circ} \mathrm{C}$ for $16 \mathrm{~h}$ in air to get the hollow spherical $\mathrm{Li}_{1.2} \mathrm{Mn}_{0.54} \mathrm{Ni}_{0.13} \mathrm{Co}_{0.13} \mathrm{O}_{2}$ samples which are named as $\mathrm{H} 1, \mathrm{H} 2$ and $\mathrm{H} 3$ accordingly(conventional particles named as $\mathrm{H} 0$ ). The $\mathrm{Zr}$ compound coated hollow spherical $\mathrm{Li}_{1.2} \mathrm{Mn}_{0.54} \mathrm{Ni}_{0.13} \mathrm{Co}_{0.13} \mathrm{O}_{2}$ (the quality fractions of $\mathrm{Zr}$ compound is $2 \%$ ) was prepared by a solution method. Stoichiometric $\mathrm{LiOH} \cdot \mathrm{H}_{2} \mathrm{O}$ and $\mathrm{Zr}\left(\mathrm{NO}_{3}\right)_{2}$ in a molar ratio of $2: 1$ were completely dissolved in absolute ethanol. The sample $\mathrm{H} 2$ was added into the solution under vigorous stirring. After evaporating the solvent at $80{ }^{\circ} \mathrm{C}$ for $5 \mathrm{~h}$, the obtained powders were calcinated at $500{ }^{\circ} \mathrm{C}$ for $6 \mathrm{~h}$ to obtain the $\mathrm{Zr}$ compound coated hollow spherical $\mathrm{Li}_{1.2} \mathrm{Mn}_{0.54} \mathrm{Ni}_{0.13} \mathrm{Co}_{0.13} \mathrm{O}_{2}$.

X-ray diffraction (XRD) and scanning electron microscopy (SEM) are employed to identify the crystalline phase and morphology of the samples. The cross-section views of hollow spherical particles were prepared in an epoxy mount and polished. The electrochemical performance was performed using a two-electrode coin-type cell (CR2025) of Li | LiPF6 (EC: EMC: DMC = 1: 1: 1 in volume) $\mid \mathrm{Li}_{1.2} \mathrm{Mn}_{0.54} \mathrm{Ni}_{0.13} \mathrm{Co}_{0.13} \mathrm{O}_{2}$. Electrode films consisting of the $\mathrm{Li}_{1.2} \mathrm{Mn}_{0.54} \mathrm{Ni}_{0.13} \mathrm{Co}_{0.13} \mathrm{O}_{2}$ cathode materials are prepared by a slurry coating technique. $\mathrm{Li}_{1.2} \mathrm{Mn}_{0.54} \mathrm{Ni}_{0.13} \mathrm{Co}_{0.13} \mathrm{O}_{2}$ powder, conductive carbon, and PVDF binder are mixed in a ratio of 8:1:1 in N-methylpyrrolidinone (NMP) 
solvent and stirred for uniform slurry. The slurry is then coated on an aluminum foil to make the electrode film, followed by drying overnight at $120^{\circ} \mathrm{C}$ in an air dry oven. Electrodes are punched in the form of $12 \mathrm{~mm}$ diameter disks. A polypropylene micro-porous film is used as the separator. The assembly of the cells is carried out in an argon-filled glove box. The cells are charged and discharged over a voltage range of 2.5-4.6 V versus $\mathrm{Li} / \mathrm{Li}^{+}$electrode at current densities of 12.5-250 $\mathrm{mAg}^{-1}$ at room temperature. Inductively coupled plasma (ICP) has been used to test the quantity of Mn dissolute in electrolyte after these electrodes cycled 100 times at $250 \mathrm{mAg}^{-1}$. Electrochemical impedance spectroscopy (EIS) was utilized to analyze problems of dynamics in the frequency range from $0.1 \mathrm{MHz}$ to $0.01 \mathrm{~Hz}$.

\section{Results and discussion}

The X-ray diffraction patterns of different $\mathrm{Li}_{1.2} \mathrm{Mn}_{0.54} \mathrm{Ni}_{0.13} \mathrm{Co}_{0.13} \mathrm{O}_{2}$ cathode materials are given in Fig.1. As it can be seen from Fig.1, all the peaks can be indexed based on the R3m structure, except for the peaks between $20^{\circ}$ and $25^{\circ}$, those are caused by super-lattice ordering of $\mathrm{Li}, \mathrm{Mn}, \mathrm{Ni}$ and $\mathrm{Co}$ atoms in the layered structure with $\mathrm{Li}_{2} \mathrm{MnO}_{3}$-type character.[22-24] In addition, higher values of $I_{(003)} / I_{(104)}$, at range of 1.923-1.981(which lists in the Table 1), also confirms an ideal structure.[25] Furthermore, as presented in the Table 1, the lattice parameters of conventional and hollow spherical $\mathrm{Li}_{1.2} \mathrm{Mn}_{0.54} \mathrm{Ni}_{0.13} \mathrm{Co}_{0.13} \mathrm{O}_{2}$ are $a=2.8508-2.8516 \AA$ and $c=14.2007-14.2232 \AA$, which are consistent with other reports with a small range.[26, 27] Obviously, based on the analysis above-mentioned, conventional and hollow spherical particles all have got similar and nice crystal structure.

Fig. 2 shows surface morphology of these $\mathrm{Li}_{1.2} \mathrm{Mn}_{0.54} \mathrm{Ni}_{0.13} \mathrm{Co}_{0.13} \mathrm{O}_{2}$ particles, the conventional particles consisting of a number of primary particles have a size of under $2 \mu \mathrm{m}$, and 
the primary particles are easier to forming particles agglomeration, as shown in Fig.2 (a) and (b). The surface of hollow spherical particles become more compact and smooth with the increase of shell thickness, which may have benefits on the resistance of corrosion from electrolyte. Furthermore, specific surface areas of $\mathrm{H} 0, \mathrm{H} 1, \mathrm{H} 2$ and $\mathrm{H} 3$ are calculated to be $3.3467,0.8433$, 0.5484 and $0.3994 \mathrm{~m}^{2} \mathrm{~g}^{-1}$ via the Brunauer-Emmett-Teller (BET) method. Sample H1 own the highest specific surface area around the hollow spherical particles maybe the result of structure collapses of particles, which can be found in the Fig. 2(d), and the structure collapse is most likely due to the shell thickness is too thin to remain structural stability. Therefore, the inner structure and shell thickness of $\mathrm{Li}_{1.2} \mathrm{Mn}_{0.54} \mathrm{Ni}_{0.13} \mathrm{Co}_{0.13} \mathrm{O}_{2}$ particles have been investigated by cross sections, as illustrated in Fig. 3. As can be seen from Fig. 3, the agglomeration randomly happened among conventional small particles can be proved clearly within broken white lines on the Fig.3 (a), which will results in the distance of lithium ion diffusion have increased. To be more specific, these conventional small particles appearances a strong possibility to forming larger particles with a size ranges in width from 2.3 to $4.2 \mu \mathrm{m}$, even more large particles what cannot observed in Fig.3 (a) and (b). The formation of this hollow spherical architecture maybe can explain by a mechanism analogous to the Kirkendall effect.[28] These particles illustrate a hollow spherical architecture, with the shell thickness at range from 1.2 to $2.5 \mu \mathrm{m}$. The analysis based on Fig. 2 and Fig. 3 suggests that a firm structure for hollow spherical particles can be obtained when the shell thickness reach to $1.8 \mu \mathrm{m}$ based on the particles size of 8-10 $\mu \mathrm{m}$.

As shown in Fig. 4 and Table 2, sample H0, H1, H2 and H3 deliver the specific capacities of 251, 265, 265 and $257 \mathrm{mAh} \mathrm{g}^{-1}$, at $12.5 \mathrm{mAg}^{-1}$, respectively. Hollow spherical particles show higher discharge capacities than that of conventional particle, which may benefit from the 
excellent dispersed state and short diffusion path. But the discharge capacity of hollow spherical particles declined with the shell thickness further increase, especially at high current density (H1 171 vs. $\mathrm{H} 3159 \mathrm{mAh} \mathrm{g}^{-1}$, at $250 \mathrm{~mA} \mathrm{~g}^{-1}$ ). However, as shown in Fig. 5, the cycle performance of sample $\mathrm{H} 1$ is unsatisfactory relative to its rate discharge property, the discharge capacity only represents $59.1 \%$ of the initial cycle capacity at $250 \mathrm{~mA} \mathrm{~g}^{-1}$ after 100 cycles. This unsatisfying cycle performance may be result from the structure collapse of particles, which makes more serious corrosion happened on the surface of particles. As shown in Table 3, the Mn dissolution of all the samples is worse than $\mathrm{Ni}$ and $\mathrm{Co}$ in the electrolyte, and the dissolved amount of $\mathrm{Mn}$ of conventional particles is much higher than that of hollow spherical particles, which own to the highest specific surface area of conventional particles. Additionally, the dissolved amount of $\mathrm{Mn}$ of sample H1 is higher than other hollow spherical samples, which may due to the increased specific surface area result from particles collapse, and then leads to a worse cycle performance than sample $\mathrm{H} 2$ and $\mathrm{H} 3$. However, the cycle performance gets worse with the shell thickness increase, which may due to the increase of electronic and ionic resistance.

Although this hollow spherical structure can help the lithium rich layered oxides to resist the corrosion from electrolyte, because of the low specific surface area they represent. However, these hollow spherical particles still exposed to the corrosive electrolyte directly. Therefore, we further covered these hollow spherical particles with a layer of $\mathrm{Li}_{2} \mathrm{ZrO}_{3}$, which can be clearly seen from Fig. 6 (c). These surface indentations on the surface of $\mathrm{Zr}$ compound coated particles are no longer as noticeable as bare hollow spherical particles, as shown in Fig.6 (b-c). Obviously, the Zr compound coating layer has a slight effect on lattice parameters, but can hardly influence the crystal structrure of hollow spherical particles, which can definitely confirmed by Fig.1 and Table 1. As shown in Fig.6 
(d-f), reveals that the formed powders are highly crystalline, and a coating layer (about $7.3 \mathrm{~nm}$ ) can be easily observed on the surface of $\mathrm{Zr}$ compound coated particles.

As shown in Fig. 7, these materials with different kinds of structure show different trends of capacity fade when the current density increased. When current density as low as $12.5 \mathrm{mAg}^{-1}$, the distinction of polarization of different materials is inconspicuous, the $\mathrm{Zr}$ compound coated particles displays a lower reversible capacities than that of bare hollow spherical particles, which may because the capacity contribution of $\mathrm{Zr}$ compound coating layer can not make up the capacity loss of equal quality lithium rich layered oxides. However, when current density increased from 12.5 to $250 \mathrm{mAg}^{-1}$, the $\mathrm{Zr}$ compound coated particle delivers the highest discharge capacity, which may due to the $\mathrm{Zr}$ compound coating layer can protect the hollow spherical particles away from the corrosive electrolyte, and then effectively prevent the Mn dissolution in electrolyte, as listed in Table 3, which means Zr compound coated particles can maintain a good crystal structure during the electrode process. Meanwhile, the $\mathrm{Zr}$ compound coated particle shows the highest capacity retention, representing $143 \mathrm{mAhg}^{-1}$ after 100 cycles at $250 \mathrm{~mA} \mathrm{~g}^{-1}$. In sharp contrast, the conventional particle only delivered a much lower discharge capacity of $83 \mathrm{mAhg}^{-1}$. After 100 cycles at $250 \mathrm{~mA} \mathrm{~g}^{-1}$, the crystal structures of those three materials have been investigated by HRTEM, as shown in Fig.6 (g-i). Obviously, the crystal structure of conventional articles become unordered, and the distance between two lattice fringes become widening after these cycles. Although, about hollow spherical particles, the crystal structure of some region area become unordered, pointed out by the arrow and circle in Fig.6 (h) marked number 1, 2. Even so, the performance of hollow spherical particles is better than the small amorphous particles[21], because partial region of the material remains integrity crystal structure, which ensures a better 
electrochemical properties of hollow spherical particles. Furthermore, as illustrated in Fig.6 (i), this $\mathrm{Zr}$ compound coating layer can effectively prevent these crystal structure changes during the electrode process, which may be the direct reason for $\mathrm{Zr}$ compound coated particle to represent the best electrochemical properties.

To gain insight into the reason that these three different particles display different electrochemical properties, the electrochemical impedance spectroscopies (EIS) of these $\mathrm{Li}_{1.2} \mathrm{Mn}_{0.54} \mathrm{Ni}_{0.13} \mathrm{Co}_{0.13} \mathrm{O}_{2}$ particles are measured, and these obtained plots consist of a semicircle arc and a straight line, which are attributed to the charge transfer process and the lithium diffusion process in the oxide structure, respectively.[29, 30] These plots are well fitted using the electric equivalent circuit shown in the inset figure of Fig. 8(a). In the equivalent circuit, $R_{s}$ and $R_{c t}$ represent the solution resistance and charge-transfer resistance, respectively. CPE is related to the double layer capacitance and passivation film capacitance. $Z_{\mathrm{W}}$ represents the Warburg impedance ( $Z^{\prime}$ is the real impedance and $Z$ " is the imaginary impedance). The parameters of the equivalent circuit are listed in Table 4. Additionally, those exchange current densities $\left(i^{0}\right)$ are calculated by the formula $\left(i^{0}=\mathrm{RT} / \mathrm{nFR}_{\mathrm{ct}}\right.$, where $\mathrm{n}$ is the number of transferred electrons) and list in Table 4. Obviously, the solution resistances are very similar and small, and the $\mathrm{Zr}$ compound coated particles shows the lowest charge transfer resistance, which may benefited from the coefficient of hollow spherical structure and $\mathrm{Zr}$ compound coating layer. Additionally, the charge transfer resistance increased with the shell thickness increase and the trend of lithium ion diffusion coefficient changed in opposite direction. The plots of the real axis $Z_{r e} v$ s. the reciprocal square root of the lower angular frequencies $\omega^{-0.5}$ are illustrated in Fig. 8(b).[31, 32] This relation is governed by Eq. (1). According to Fig. 8(b) and Eq. (2), the slope of the straight lines represents 
the values of Warburg impedance coefficient ( $\sigma_{\mathrm{w}}$, list in Table 4). The diffusion coefficients (D) of the lithium ions diffusing into the bulk electrode materials are calculated using Eq. (2) and recorded in Table 4. Notably, sample H1 show the lowest resistance for lithium ion diffusion process owning to its shortest diffusion length, as shown in Fig.3. In addition, this hollow spherical structure has a greater influence on lithium ion diffusion coefficient than charge transfer resistance. Specifically, the lithium ion diffusion coefficient of conventional particles is $7.43 \times 10^{-16}$, and the hollow spherical structure help to raise these lithium ion diffusion coefficients to (H1) $8.92 \times 10^{-15}$, (H2) $4.16 \times 10^{-15}$ and (H1) $3.70 \times 10^{-16} \mathrm{~cm}^{2} \mathrm{~s}^{-1}$, and $\mathrm{Zr}$ compound coating layer can further modificate the electronic and ionic transmission capacities to some extent at the same time. Furthermore, after 100 cycles at $250 \mathrm{mAg}^{-1}$, the charge-transfer resistance of pristine materials increase shapely to $806.60 \Omega$ and lithium ion diffusion coefficient decrease remarkably to $2.01 \times 10^{-16} \mathrm{~cm}^{2} \mathrm{~s}^{-1}$, as illustrated in Fig. 9 and Table 4. On the contrary, the hollow spherical structure and $\mathrm{Zr}$ compound coating layer can effectively prevent the deterioration of electronic and ionic transmission capacity, which are in good agreement with the analysis of HRTEM analysis above. Therefore, based on the discussion mentioned above, a surface modification combine with the design of hollow spherical structure with an appropriate shell thickness can effectively enhance these electrochemical properties of lithium ion layered oxides.

$$
\begin{aligned}
& Z_{\mathrm{re}}=\mathrm{R}_{\mathrm{s}}+R_{c t}+\sigma_{W} \cdot \omega^{-0.5} \\
& \mathrm{D}=0.5\left(\frac{\mathrm{RT}}{\mathrm{AF}_{\mathrm{W}}^{2} \mathrm{C}}\right)^{2}
\end{aligned}
$$

Where $\omega$, angular frequency region; $\mathrm{R}$, the gas constant; $\mathrm{T}$, the absolute temperature; $\mathrm{F}$, Faraday's constant; $\mathrm{A}$, the area of the electrode surface; and $\mathrm{C}$, molar concentration of $\mathrm{Li}^{+}$ions. 


\section{Conclusion}

In summary, the lithium rich layered oxides with different morphologies are synthesized by co-precipitation followed by calcination. The hollow spherical structure can markedly decrease the specific surface area of lithium rich layer oxides, and then weaken the Mn dissolution in corrosive electrolyte. In addition, the thinner the shell thickness is, the higher the electronic and ionic conductivities are, which bring a better rate capacity to hollow spherical $\mathrm{Li}_{1.2} \mathrm{Mn}_{0.54} \mathrm{Ni}_{0.13} \mathrm{Co}_{0.13} \mathrm{O}_{2}$ particles. However, the structure of hollow particles becomes fragile when the shell thickness smaller than $1.8 \mu \mathrm{m}$, which should result in a bigger specific surface area that means more corrosion from electrolyte. Further modified the surface of hollow spherical particles with $\mathrm{Zr}$ compound can improve the electronic and ionic transmission capacities to some extent at the same time.This study shows that an appropriate surface modification based on the optimal structure design is significant in the development of lithium rich manganese layered oxides.

\section{Acknowledgements}

This work was supported by the Initial Research Founds for Young Teachers of Donghua University, the National Science Foundation of China (NSFC) (No. 21377023 and 51604081) and China Postdoctoral Science Foundation (No. 2016M600269).

\section{References}

[1] L. Li, Z. Chen, Q. Zhang, M. Xu, X. Zhou, H. Zhua, K. Zhang, A hydrolysis-hydrothermal route for the synthesis of ultrathin $\mathrm{LiAlO}_{2}$-inlaid $\mathrm{LiNi}_{0.5} \mathrm{Co}_{0.2} \mathrm{Mn}_{0.3} \mathrm{O}_{2}$ as a high-performance cathode material for lithium ion batteries, J. Mater. Chem. A, 3 (2015) 894-904.

[2] J.-f. Zhang, C. Shen, B. Zhang, J.-c. Zheng, C.-1. Peng, X.-w. Wang, X.-b. Yuan, H. Li, G.-m. Chen, Synthesis and performances of $2 \mathrm{LiFePO}_{4} \cdot \mathrm{Li}_{3} \mathrm{~V}_{2}\left(\mathrm{PO}_{4}\right)_{3} / \mathrm{C}$ cathode materials via spray drying 
method with double carbon sources, Journal of Power Sources, 267 (2014) 227-234.

[3] Z. Wang, Y. Yin, Y. Ren, Z. Wang, M. Gao, T. Ma, W. Zhuang, S. Lu, A. Fan, K. Amine, Z. Chen, High performance lithium-manganese-rich cathode material with reduced impurities, Nano Energy, 31 (2017) 247-257.

[4] Y. Li, C. Wu, Y. Bai, L. Liu, H. Wang, F. Wu, N. Zhang, Y. Zou, Hierarchical Mesoporous Lithium-Rich $\mathrm{Li}\left[\mathrm{Li}_{0.2} \mathrm{Ni}_{0.2} \mathrm{Mn}_{0.6}\right] \mathrm{O}_{2}$ Cathode Material Synthesized via Ice Templating for Lithium-Ion Battery, ACS applied materials \& interfaces, 8 (2016) 18832-18840.

[5] L. Li, M. Xu, Z. Chena, X. Zhou, Q. Zhang, H. Zhua, C. Wub, K. Zhang, High-performance lithium-rich layered oxide materials Effects of chelating agents on microstructure and electrochemical properties, Electrochimica Acta 174 ( 2015) 446-455.

[6] E. Zhao, X. Liu, H. Zhao, X. Xiao, Z. Hu, Ion conducting $\mathrm{Li}_{2} \mathrm{SiO}_{3}$-coated lithium-rich layered oxide exhibiting high rate capability and low polarization, Chem. Commun., 51 (2015) 9093-9096.

[7] P. Yan, A. Nie, J. Zheng, Y. Zhou, D. Lu, X. Zhang, R. Xu, I. Belharouak, X. Zu, J. Xiao, K. Amine, J. Liu, F. Gao, R. Shahbazian-Yassar, J.G. Zhang, C.M. Wang, Evolution of lattice structure and chemical composition of the surface reconstruction layer in $\mathrm{Li}_{1.2} \mathrm{Ni}_{0.2} \mathrm{Mn}_{0.6} \mathrm{O}_{2}$ cathode material for lithium ion batteries, Nano letters, 15 (2015) 514-522.

[8] F. Dogan, B.R. Long, J.R. Croy, K.G. Gallagher, H. Iddir, J.T. Russell, M. Balasubramanian, B. Key, Re-entrant lithium local environments and defect driven electrochemistry of Li- and Mn-rich Li-ion battery cathodes, Journal of the American Chemical Society, 137 (2015) 2328-2335.

[9] W. Tu, P. Xia, X. Zheng, C. Ye, M. Xu, W. Li, Insight into the interaction between layered lithium-rich oxide and additive-containing electrolyte, Journal of Power Sources, 341 (2017) 
348-356.

[10] N. Yabuuchi, K. Yoshii, S.T. Myung, I. Nakai, S. Komaba, Detailed studies of a high-capacity electrode material for rechargeable batteries, $\mathrm{Li}_{2} \mathrm{MnO}_{3}-\mathrm{LiCo}_{1 / 3} \mathrm{Ni}_{1 / 3} \mathrm{Mn}_{1 / 3} \mathrm{O}_{2}$, Journal of the American Chemical Society, 133 (2011) 4404-4419.

[11] X. Yu, Y. Lyu, L. Gu, H. Wu, S.-M. Bak, Y. Zhou, K. Amine, S.N. Ehrlich, H. Li, K.-W. Nam, X.-Q. Yang, Understanding the Rate Capability of High-Energy-Density Li-Rich Layered $\mathrm{Li}_{1.2} \mathrm{Ni}_{0.15} \mathrm{Co}_{0.1} \mathrm{Mn}_{0.55} \mathrm{O}_{2}$ Cathode Materials, Adv. Energy Mater. , 4 (2014) 1300950.

[12] W. Wei, L. Chen, A. Pan, D.G. Ivey, Roles of surface structure and chemistry on electrochemical processes in lithium-rich layered oxide cathodes, Nano Energy, 30 (2016) $580-602$.

[13] Y.C. Jin, J.G. Duh, Fluorination Induced the Surface Segregation of High Voltage Spinel on Lithium-Rich Layered Cathodes for Enhanced Rate Capability in Lithium Ion Batteries, ACS applied materials \& interfaces, 8 (2016) 3883-3891.

[14] X. Zhang, S. Sun, Q. Wu, N. Wan, D. Pan, Y. Bai, Improved electrochemical and thermal performances of layered $\mathrm{Li}\left[\mathrm{Li}_{0.2} \mathrm{Ni}_{0.17} \mathrm{Co}_{0.07} \mathrm{Mn}_{0.56}\right] \mathrm{O}_{2}$ via $\mathrm{Li}_{2} \mathrm{ZrO}_{3}$ surface modification, Journal of Power Sources, 282 (2015) 378-384.

[15] K.J. Rosina, M. Jiang, D. Zeng, E. Salager, A.S. Best, C.P. Grey, Structure of aluminum fluoride coated $\mathrm{Li}\left[\mathrm{Li}_{1 / 9} \mathrm{Ni}_{1 / 3} \mathrm{Mn}_{5 / 9}\right] \mathrm{O}_{2}$ cathodes for secondary lithium-ion batteries, Journal of Materials Chemistry, 22 (2012) 20602.

[16] Y. Xin, L. Qi, Y. Zhang, Z. Zuo, H. Zhou, X. Zhang, Organic solvent-assisted free-standing $\mathrm{Li}_{2} \mathrm{MnO}_{3} \cdot \mathrm{LiNi}_{1 / 3} \mathrm{Co}_{1 / 3} \mathrm{Mn}_{1 / 3} \mathrm{O}_{2}$ on 3D graphene as a high energy density cathode, Chem. Commun., 51 (2015) 16381-16384 
[17] S.J. Shi, J.P. Tu, Y.J. Mai, Y.Q. Zhang, C.D. Gu, X.L. Wang, Effect of carbon coating on electrochemical performance of $\mathrm{Li}_{1.048} \mathrm{Mn}_{0.381} \mathrm{Ni}_{0.286} \mathrm{Co}_{0.286} \mathrm{O}_{2}$ cathode material for lithium-ion batteries, Electrochimica Acta, 63 (2012) 112-117.

[18] J. Liu, Q. Wang, B. Reeja-Jayan, A. Manthiram, Carbon-coated high capacity layered $\mathrm{Li}\left[\mathrm{Li}_{0.2} \mathrm{Mn}_{0.54} \mathrm{Ni}_{0.13} \mathrm{Co}_{0.13}\right] \mathrm{O}_{2}$ cathodes, Electrochemistry Communications, 12 (2010) 750-753.

[19] Y. Xin, L. Qi, Y. Zhang, Z. Zuo, H. Zhou, X. Zhang, Organic solvent-assisted free-standing $\mathrm{Li}_{2} \mathrm{MnO}_{3} \cdot \mathrm{LiNi}_{1 / 3} \mathrm{Co}_{1 / 3} \mathrm{Mn}_{1 / 3} \mathrm{O}_{2}$ on $3 \mathrm{D}$ graphene as a high energy density cathode, Chem. Commun., $51(2015)$ 16381-16384.

[20] Z. He, Z. Wang, H. Guo, X. Li, W. Xianwen, P. Yue, J. Wang, A simple method of preparing graphene-coated $\mathrm{Li}\left[\mathrm{Li}_{0.2} \mathrm{Mn}_{0.54} \mathrm{Ni}_{0.13} \mathrm{Co}_{0.13}\right] \mathrm{O}_{2}$ for lithium-ion batteries, Materials Letters, 91 (2013) 261-264.

[21] Z. He, Z. Wang, Z. Huang, H. Chen, X. Li, H. Guo, A novel architecture designed for lithium rich layered $\mathrm{Li}\left[\mathrm{Li}_{0.2} \mathrm{Mn}_{0.54} \mathrm{Ni}_{0.13} \mathrm{Co}_{0.13}\right] \mathrm{O}_{2}$ oxides for lithium-ion batteries, J. Mater. Chem. A, 3 (2015) $16817-16823$.

[22] F. Amalraj, D. Kovacheva, M. Talianker, L. Zeiri, J. Grinblat, N. Leifer, G. Goobes, B. Markovsky, D. Aurbach, Integrated Materials $\mathrm{XLi}_{2} \mathrm{MnO}_{3} \cdot(1-\mathrm{x}) \mathrm{LiMn}_{1 / 3} \mathrm{Ni}_{1 / 3} \mathrm{Co}_{1 / 3} \mathrm{O}_{2}(\mathrm{x}=0.3,0.5,0.7)$ Synthesized, Journal of The Electrochemical Society, 157 (2010) A1121-A1130.

[23] Y.-K. Sun, M.G. Kim, S.-H. Kang, K. Amine, Electrochemical performance of layered Li $\mathrm{Li}_{0.15} \mathrm{Ni}_{0.275-\mathrm{x}} \mathrm{Mg}_{\mathrm{x}} \mathrm{Mn}_{0.575} \mathrm{O}_{2}$ cathode materials for lithium secondary batteries, J. Mater. Chem., 13 (2003) 319-322.

[24] C.S. Johnson, J.-S. Kim, A.J. Kropf, A.J. Kahaian, J.T. Vaughey, M.M. Thackeray, The role of $\mathrm{Li}_{2} \mathrm{MO}_{2}$ structures ( $\mathrm{M}=$ metal ion) in the electrochemistry of $(\mathrm{x}) \mathrm{LiMn}_{0.5} \mathrm{Ni}_{0.5} \mathrm{O}_{2} \cdot(1-\mathrm{x}) \mathrm{Li}_{2} \mathrm{TiO}_{3}$ 
electrodes for lithium-ion batteries, Electrochemistry Communications, 4 (2002) 492-498.

[25] S.-H. Kang, P. Kempgens, S. Greenbaum, A.J. Kropf, K. Amine, M.M. Thackeray, Interpreting the structural and electrochemical complexity of $0.5 \mathrm{Li}_{2} \mathrm{MnO}_{3} \cdot 0.5 \mathrm{LiMO}_{2}$ electrodes for lithium batteries $\left(\mathrm{M}=\mathrm{Mn}_{0.52 \mathrm{x}} \mathrm{Ni}_{0.52 \mathrm{x}} \mathrm{Co}_{2 \mathrm{x}}, 0 \leqslant \mathrm{x} \leqslant 0.5\right)$, J. Mater. Chem., 17 (2007) 2069 2077.

[26] A. Ito, D. Li, Y. Sato, M. Arao, M. Watanabe, M. Hatano, H. Horie, Y. Ohsawa, Cyclic deterioration and its improvement for Li-rich layered cathode material $\mathrm{Li}\left[\mathrm{Ni}_{0.17} \mathrm{Li}_{0.2} \mathrm{Co}_{0.07} \mathrm{Mn}_{0.56}\right] \mathrm{O}_{2}$, Journal of Power Sources, 195 (2010) 567-573.

[27] Z. Li, F. Du, X. Bie, D. Zhang, Y. Cai, X. Cui, C. Wang, G. Chen, Y. Wei, Electrochemical Kinetics of the $\mathrm{Li}\left[\mathrm{Li}_{0.23} \mathrm{Co}_{0.3} \mathrm{Mn}_{0.47}\right] \mathrm{O}_{2}$ Cathode Material Studied by GITT and EIS, J. Phys. Chem. C, 114 (2010) 22751-22757.

[28] X.W. Lou, L.A. Archer, Z. Yang, Hollow Micro-/Nanostructures: Synthesis and Applications, Advanced Materials, 20 (2008) 3987-4019.

[29] A. Ito, D. Li, Y. Ohsawa, Y. Sato, A new approach to improve the high-voltage cyclic performance of Li-rich layered cathode material by electrochemical pre-treatment, Journal of Power Sources, 183 (2008) 344-346.

[30] L.F. Jiao, M. Zhang, H.T. Yuan, M. Zhao, J. Guo, W. Wang, X.D. Zhou, Y.M. Wang, Effect of $\mathrm{Cr}$ doping on the structural, electrochemical properties of $\mathrm{Li}\left[\mathrm{Li}_{0.2} \mathrm{Ni}_{0.2-\mathrm{x} / 2} \mathrm{Mn}_{0.6-\mathrm{x} / 2} \mathrm{Cr}_{\mathrm{x}}\right] \mathrm{O}_{2}(\mathrm{x}=0$, $0.02,0.04,0.06,0.08)$ as cathode materials for lithium secondary batteries, Journal of Power Sources 167 (2007) 178-184.

[31] C.J. Jafta, K.I. Ozoemena, M.K. Mathe, W.D. Roos, Synthesis, characterisation and electrochemical intercalation kinetics of nanostructured aluminium-doped 
$\mathrm{Li}\left[\mathrm{Li}_{0.2} \mathrm{Mn}_{0.54} \mathrm{Ni}_{0.13} \mathrm{Co}_{0.13}\right] \mathrm{O}_{2}$ cathode material for lithium ion battery, Electrochimica Acta, 85 (2012) 411-422.

[32] J. Lin, D. Mu, Y. Jin, B. Wu, Y. Ma, F. Wu, Li-rich layered composite $\operatorname{Li}\left[\mathrm{Li}_{0.2} \mathrm{Ni}_{0.2} \mathrm{Mn}_{0.6}\right] \mathrm{O}_{2}$ synthesized by a novel approach as cathode material for lithium ion battery, Journal of Power Sources, 230 (2013) 76-80.

\section{Table captions}

Table 1 Lattice parameters of conventional, hollow spherical and $\mathrm{Zr}$ compound coated particles

Table 2 The rate capacities of conventional and hollow spherical particles

Table $3 \mathrm{Mn}$ dissolution of conventional, hollow spherical and $\mathrm{Zr}$ compound coated particles

Table 4 The impedance parameters of conventional, hollow spherical and $\mathrm{Zr}$ compound coated particles before and after cycles

\section{Figure captions}

Fig. 1 XRD patterns of conventional, hollow spherical and $\mathrm{Zr}$ compound coated particles

Fig. 2 SEM images of (a-b) conventional particles: H0, hollow spherical particles: (c-d) H1, (e-f) $\mathrm{H} 2$ and (g-h) H3

Fig. 3 Cross sections of (a-b) conventional particles: H0, hollow spherical particles: (c-d) H1, (e-f) $\mathrm{H} 2$ and (g-h) H3

Fig. 4 Typical charge-discharge curves of conventional and hollow spherical particles

Fig. 5 Cycle properties of conventional and hollow spherical particles

Fig. 6 SEM images of (a) conventional particles: H0, (b) hollow spherical particles: H2 and (c) Zr compound coated particles: HZ; HRTEM image of conventional particles (d)/(g), hollow spherical 
particles (e)/(h) and $\mathrm{Zr}$ compound coated particles (f)/(i) before and after 100 cycles at $250 \mathrm{~mA} \mathrm{~g}^{-1}$

Fig. 7 Discharge capacities and cycle properties of conventional (H0), hollow spherical (H2) and $\mathrm{Zr}$ compound coated particles (HZ)

Fig. 8 (a) AC impedance measurement of conventional, hollow spherical and $\mathrm{Zr}$ compound coated particles before electrode process, the inset figure shows the equivalent circuit for the plot fitting, (b) Plots of Z' vs $\omega^{-1 / 2}$ of conventional, hollow spherical and $\mathrm{Zr}$ compound coated particles

Fig. 9 (a) AC impedance measurement of conventional, hollow spherical and $\mathrm{Zr}$ compound coated particles after 100 cycles at $250 \mathrm{~mA} \mathrm{~g}^{-1}$, (b) Plots of $Z^{\prime}$ vs $\omega^{-1 / 2}$ of conventional, hollow spherical and $\mathrm{Zr}$ compound coated particles 
Table 1

\begin{tabular}{ccccc}
\hline Samples & $a(\AA)$ & $c(\AA)$ & $c / a$ & $I_{(003)} / I_{(104)}$ \\
\hline H0 & 2.8510 & 14.2232 & 4.989 & 1.953 \\
H1 & 2.8516 & 14.2179 & 4.986 & 1.923 \\
H2 & 2.8510 & 14.2042 & 4.982 & 1.981 \\
H3 & 2.8508 & 14.2007 & 4.981 & 1.974 \\
HZ & 2.8813 & 14.0937 & 4.892 & 1.967 \\
\hline
\end{tabular}


Table 2

\begin{tabular}{cccccc}
\hline Samples & $12.5 \mathrm{mAg}^{-1}$ & $25 \mathrm{mAg}^{-1}$ & $50 \mathrm{mAg}^{-1}$ & $125 \mathrm{mAg}^{-1}$ & $250 \mathrm{mAg}^{-1}$ \\
\hline $\mathrm{H} 0$ & 251 & 235 & 209 & 179 & 152 \\
$\mathrm{H} 1$ & 265 & 248 & 224 & 198 & 171 \\
$\mathrm{H} 2$ & 265 & 253 & 231 & 197 & 170 \\
H3 & 257 & 241 & 215 & 184 & 159 \\
\hline
\end{tabular}


Table 3

\begin{tabular}{cccc}
\hline Samples & Mn (ppm) & Co (ppm) & Ni (ppm) \\
\hline H0 & 101.95 & 16.77 & 22.50 \\
H1 & 42.89 & 3.24 & 5.16 \\
H2 & 37.20 & 2.13 & 4.97 \\
H3 & 35.72 & 1.98 & 3.55 \\
HZ & 10.81 & 0.02 & 0.33 \\
\hline
\end{tabular}




\begin{tabular}{cccccc}
\hline Samples & $\mathrm{R}_{\mathrm{s}}(\Omega)$ & $\mathrm{R}_{\mathrm{ct}}(\Omega)$ & $\sigma_{\omega}\left(\Omega \mathrm{cm}^{2} \mathrm{~s}^{-0.5}\right)$ & $\mathrm{D}\left(\mathrm{cm}^{2} \mathrm{~s}^{-1}\right)$ & $\left.\mathrm{I}^{0}(\mathrm{~mA} \mathrm{~cm})^{-2}\right)$ \\
\hline $\mathrm{H} 0$ & 6.51 & 136.00 & 102.03 & $7.43 \times 10^{-16}$ & $1.89 \times 10^{-4}$ \\
$\mathrm{H} 1$ & 3.36 & 87.0 & 29.43 & $8.92 \times 10^{-15}$ & $2.95 \times 10^{-4}$ \\
$\mathrm{H} 2$ & 2.54 & 154.80 & 43.10 & $4.16 \times 10^{-15}$ & $1.66 \times 10^{-4}$ \\
$\mathrm{H} 3$ & 3.61 & 330.2 & 144.50 & $3.70 \times 10^{-16}$ & $7.78 \times 10^{-5}$ \\
$\mathrm{HZ}$ & 3.51 & 64.20 & 36.20 & $5.90 \times 10^{-15}$ & $4.00 \times 10^{-4}$ \\
$\mathrm{H} 0$ & 6.48 & 806.60 & 195.93 & $2.01 \times 10^{-16}$ & $3.18 \times 10^{-5}$ \\
$\begin{array}{c}\text { (after 100 cycles) } \\
\text { H2 }\end{array}$ & 11.18 & 727.00 & 169.00 & $2.71 \times 10^{-16}$ & $3.58 \times 10^{-5}$ \\
$\begin{array}{c}\text { (after 100 cycles) } \\
\text { HZ }\end{array}$ & & & & & \\
(after 100 cycles) & 12.37 & 404.80 & 100.12 & $7.71 \times 10^{-16}$ & $6.34 \times 10^{-5}$ \\
\hline
\end{tabular}




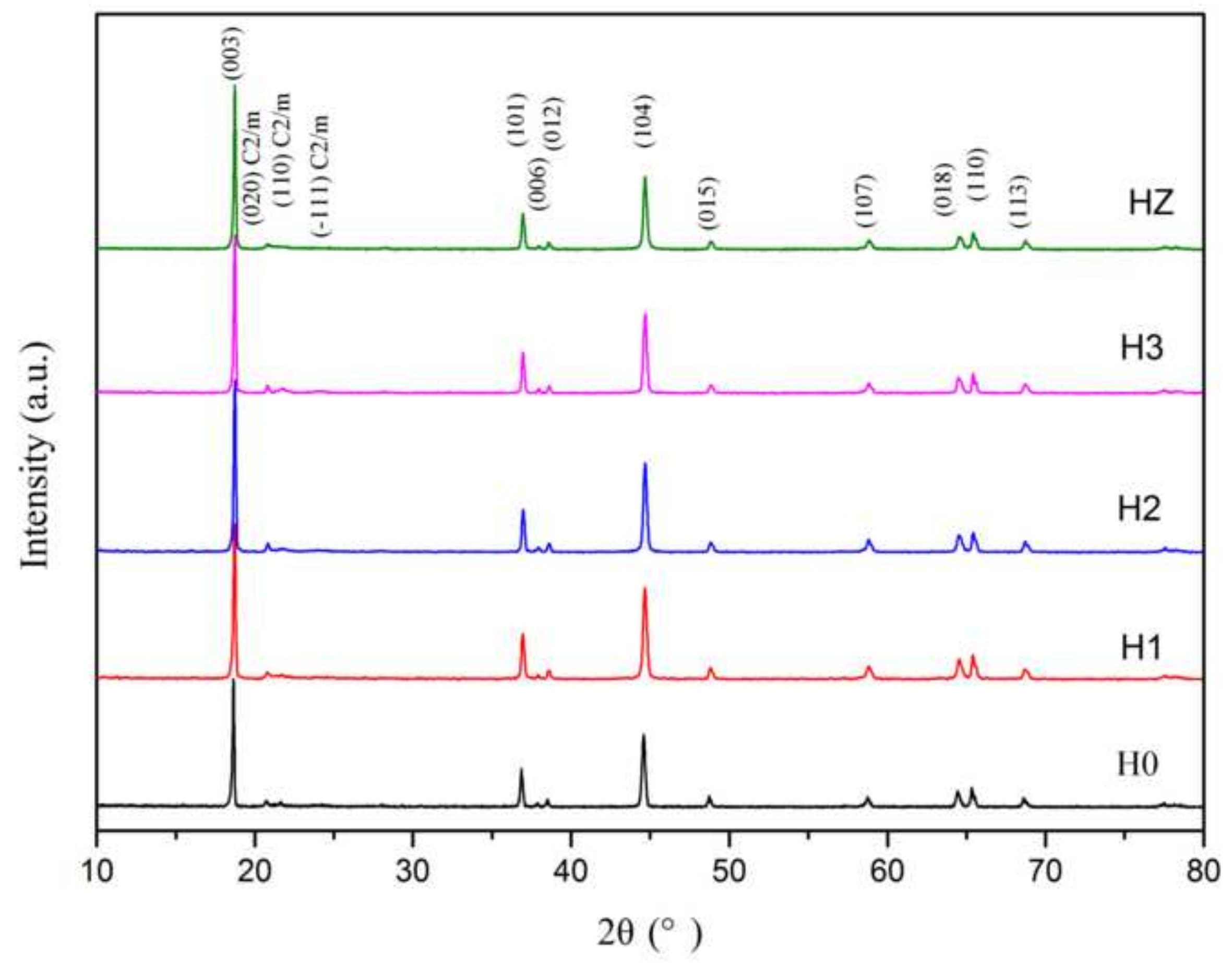



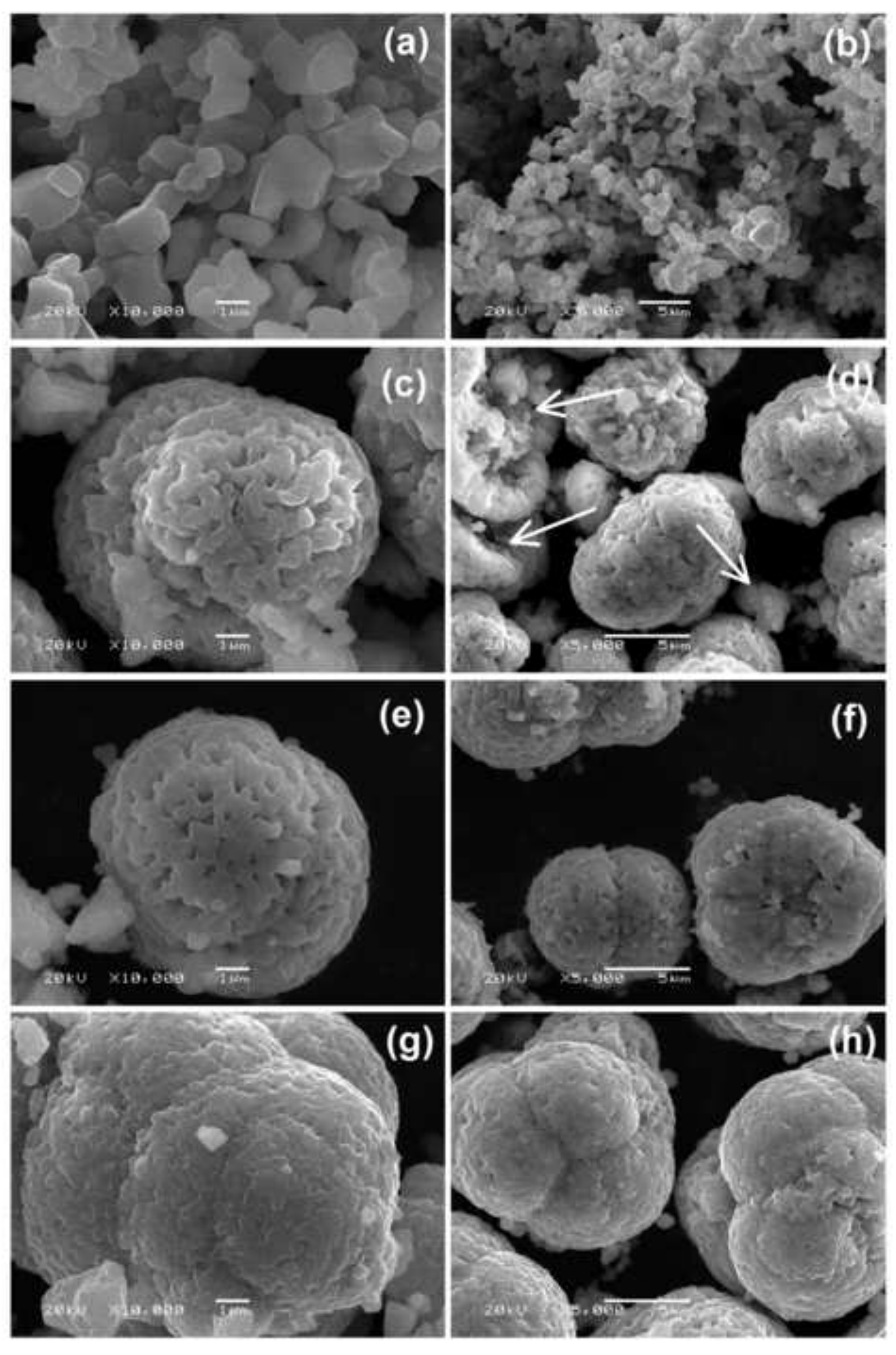


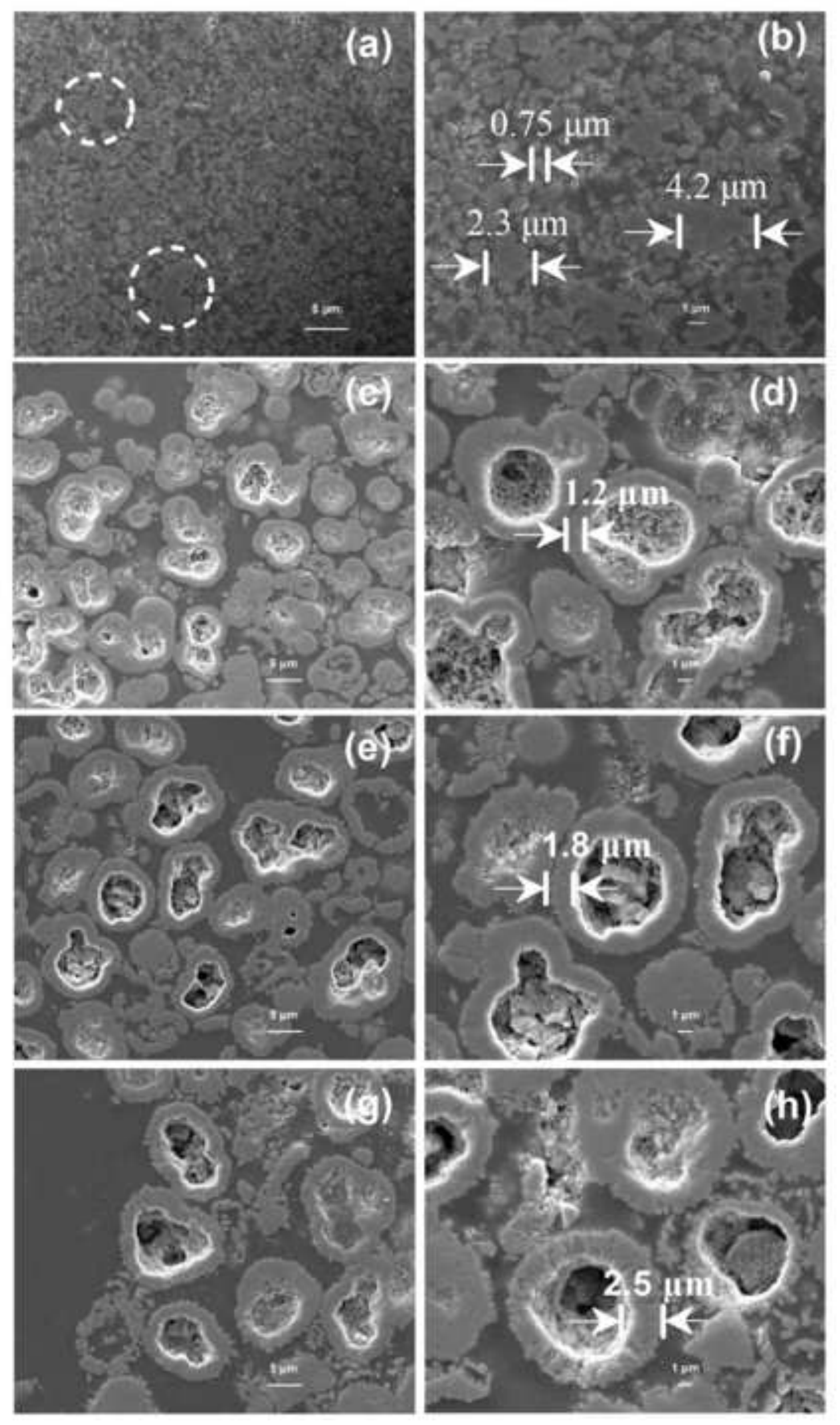




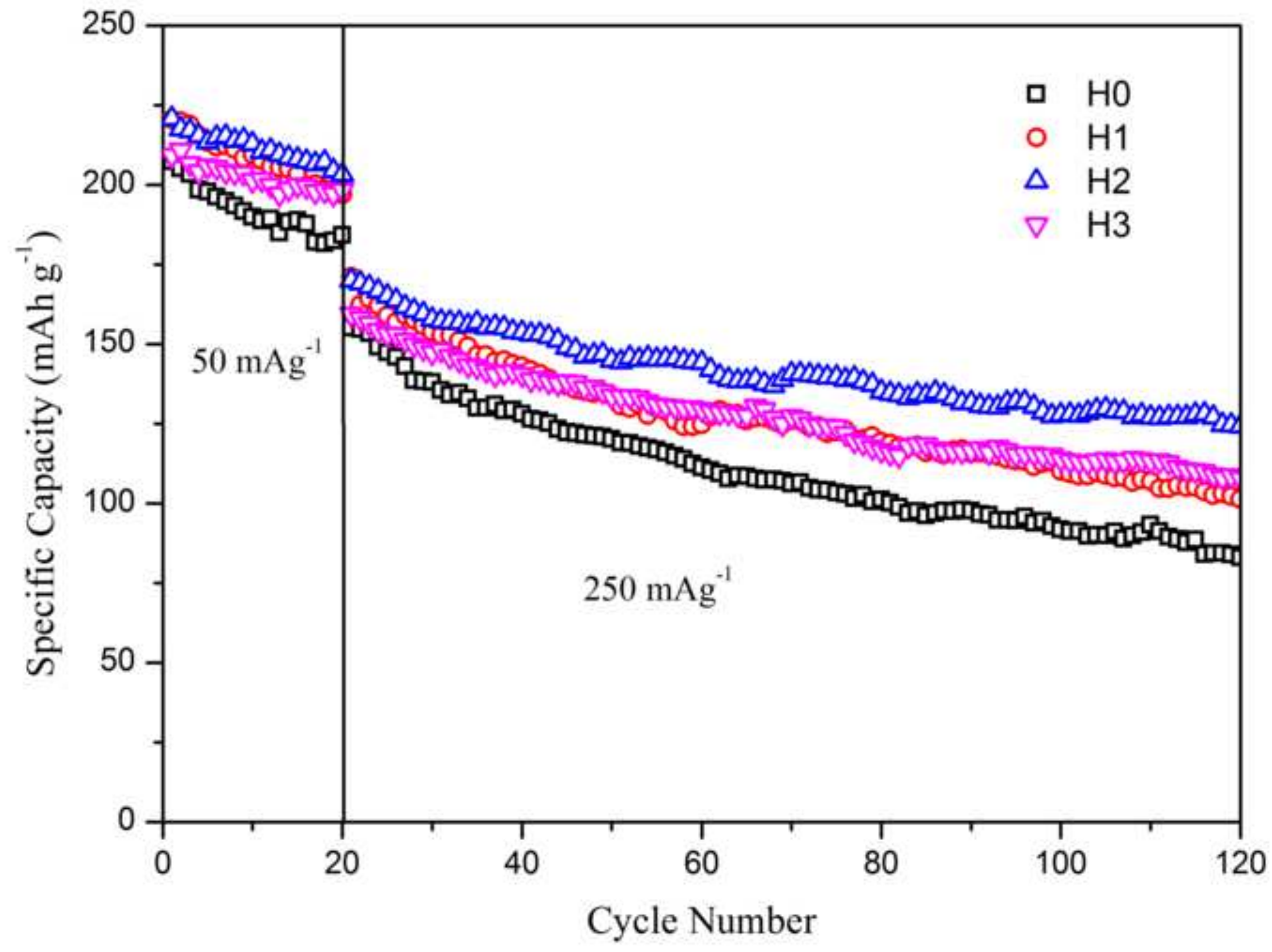




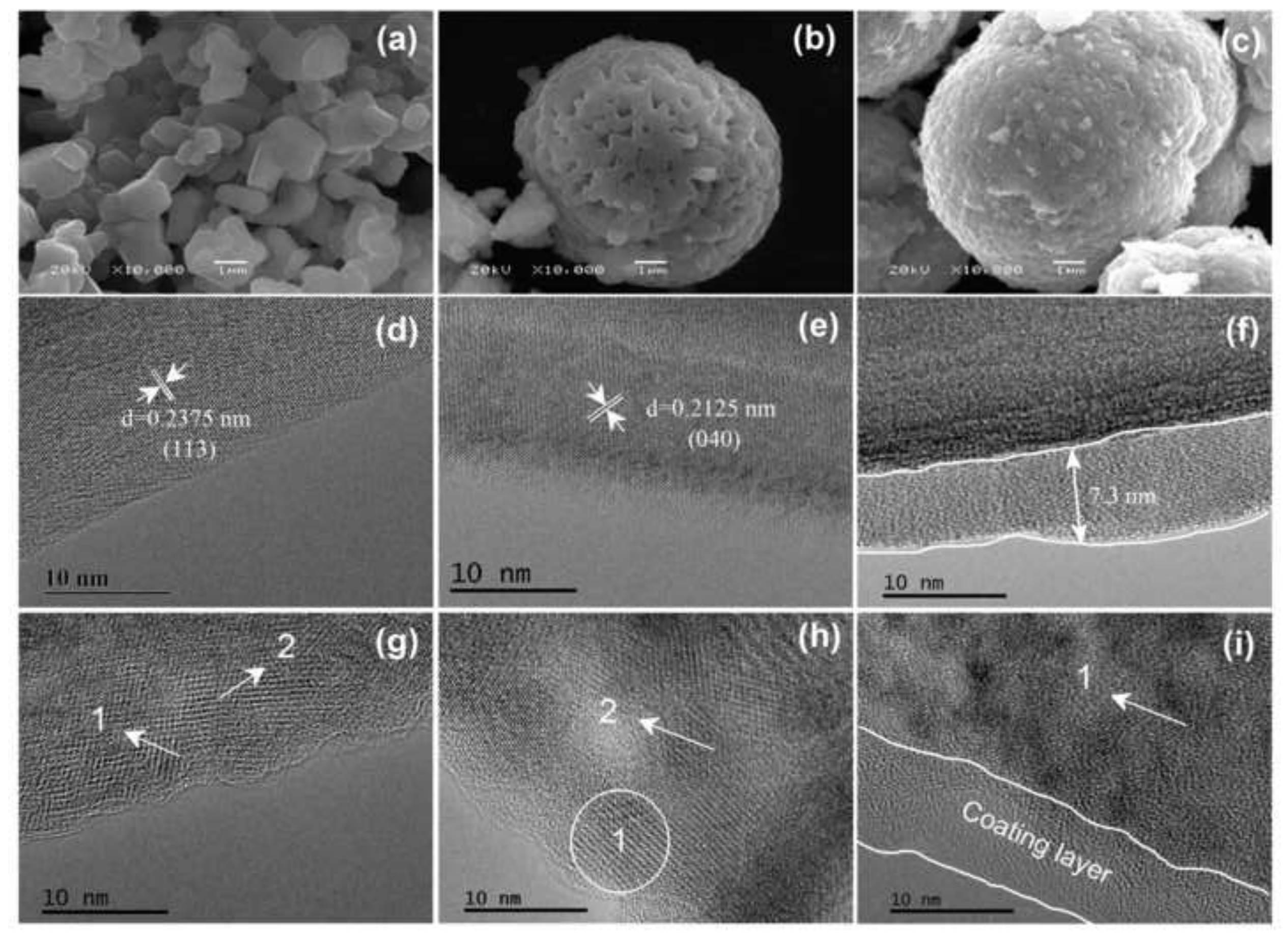




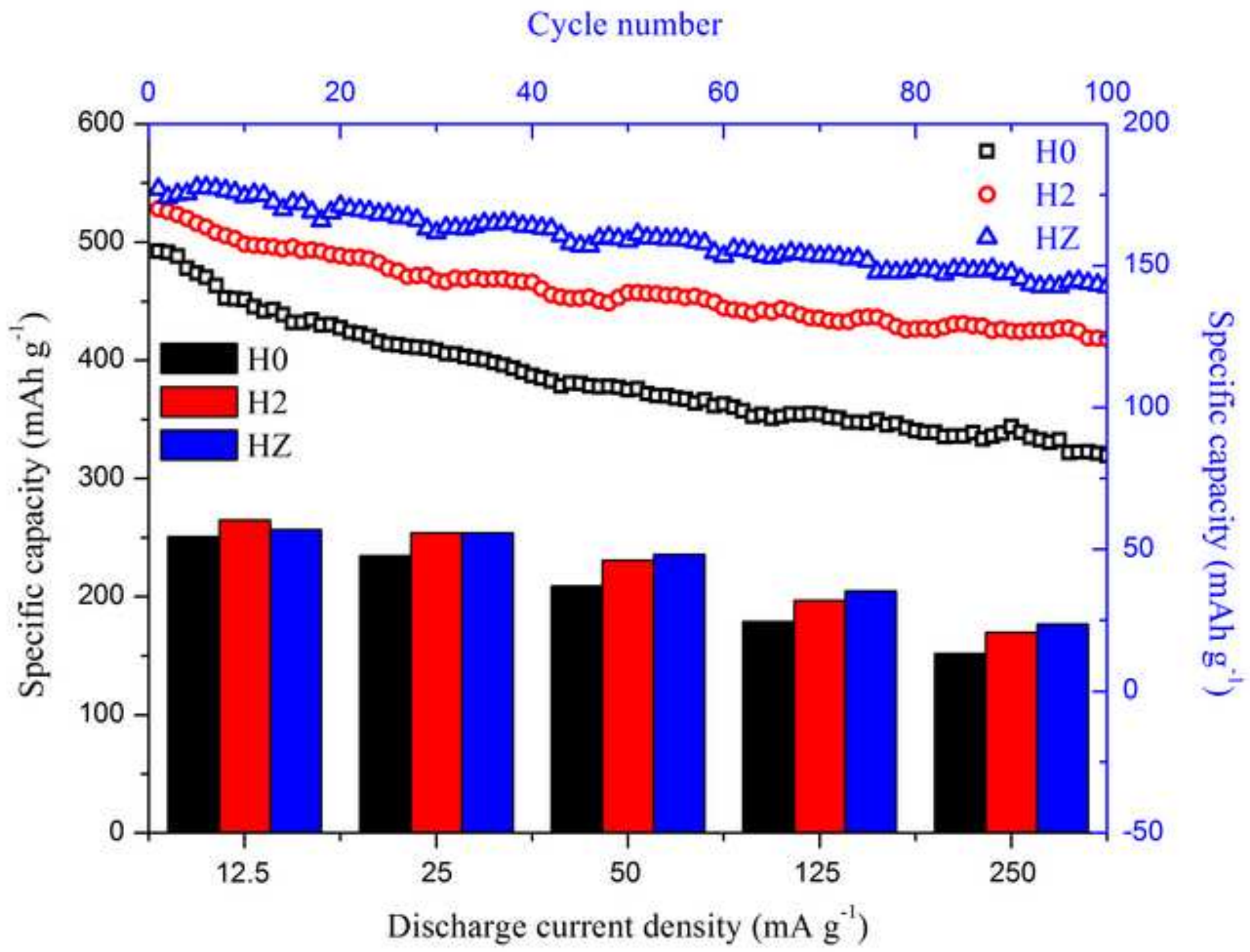



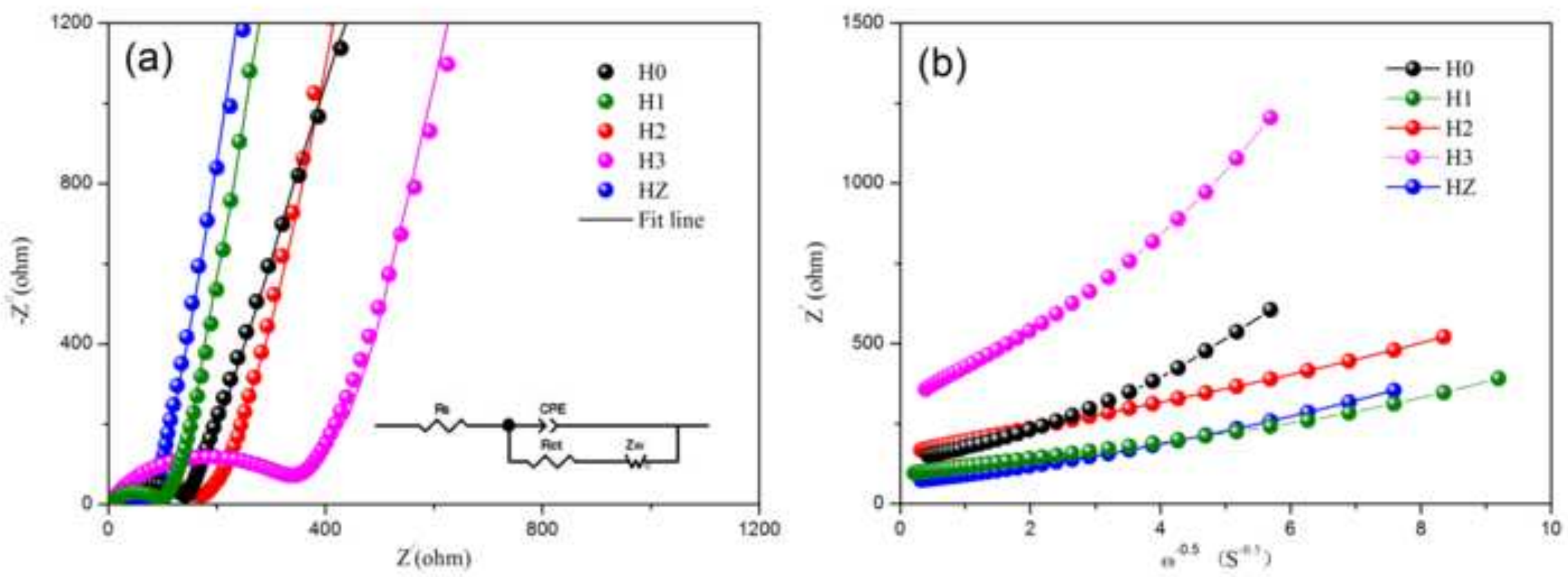

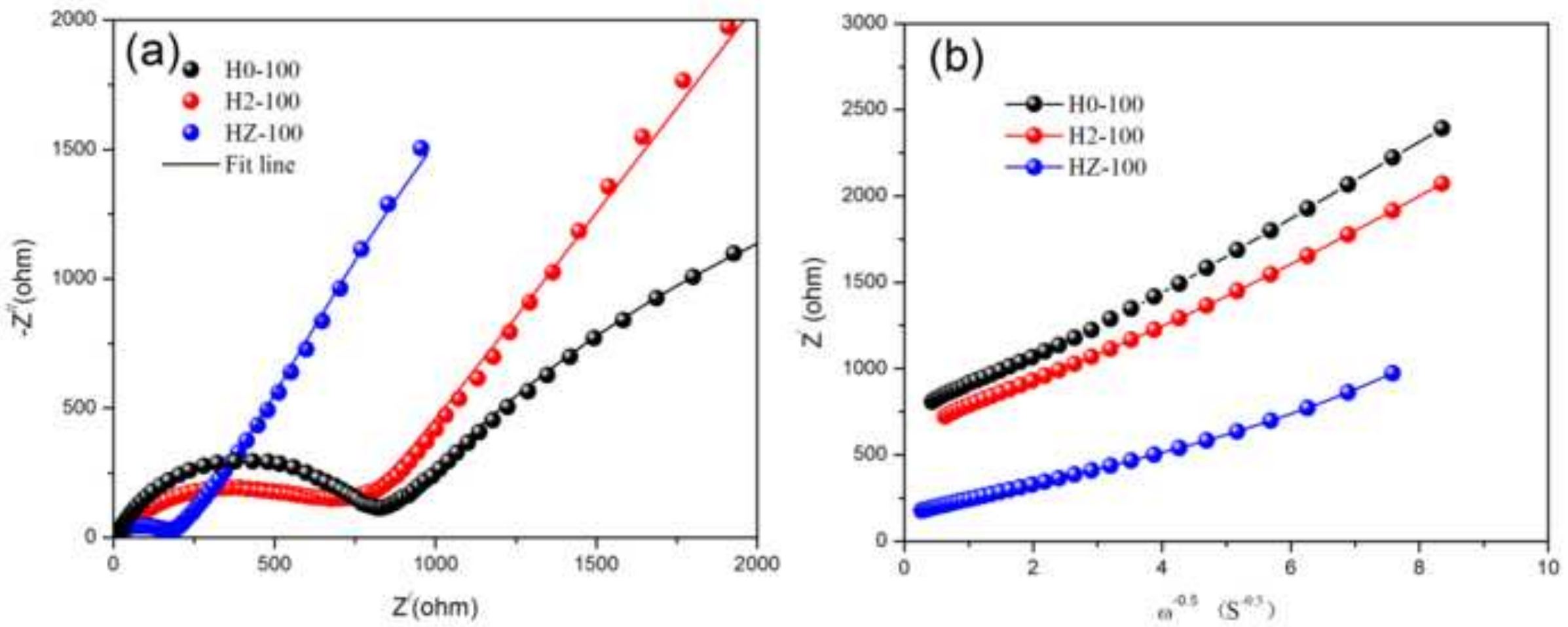